\title{
La entre-vista encuentro como método del reportaje
}

\author{
The interview I find as a method of reporting
}

\section{A entrevista de encontro como método de reportagem}

\author{
Raúl Hernando Osorio Vargas ${ }^{1}$ \\ Universidad de Antioquia - UDEA - Colômbia \\ ORCID: https://orcid.org/0000-0002-8286-7649 \\ Endereço currículo Plataforma Lattes: http://lattes.cnpq.br/4842865663324018 \\ E-mail: osoriova@gmail.com
}

\begin{abstract}
... cuanto más he escrito menos he logrado distinguir los géneros del periodismo. [...] es imposible no reconocer que la entrevista - no como género sino como método- es el hada madrina de la cual se nutren todos [...]. Nunca se aprenderá a distinguir a primera vista entre reportaje, crónica, cuento y novela. Pregúnteselo a los diccionarios y se dará cuenta de que son los que menos lo saben. Es un problema de métodos: todos los géneros mencionados tienen sus puertos de abastecimiento en investigaciones y testimonios, en libros y documentos, en interrogatorios y encuestas, y en la creatividad torrencial de la vida cotidiana Gabriel García Márquez
\end{abstract}

Resumen: Aquí son descritos y analizados los métodos de la reportería de los periodistas, especialmente los procesos del reportero como mediador-narrador. La entre-vistaencuentro implica un método que va al descubrimiento de las vivencias cotidianas, y las acoge con los afectos y las simpatías de la comprensión. En un abordaje dialógico, la narrativa teje las consideraciones y las informaciones que universalizan la situación del cotidiano. En ese camino (método) se establecen las relaciones entre la conversación, la observación y la experiencia-vivencia. Se hace una reflexión sobre la entre-vistaencuentro como método transversal del periodismo, de las investigaciones, de los testimonios, de las historias de vida y de las narrativas humanas. En mi libro El reportaje como metodología del periodismo. Una polifonía de saberes (2017) sostengo que el periodismo muestra e ilumina caminos (métodos) por medio del reportaje, que en todo el mundo ha sido muy estudiado como género periodístico, pero no bajo la dimensión de la metodología del periodismo, que ha estado oculta a las miradas de estudiosos, teóricos y académicos. En este sentido, mi propuesta constituye un giro epistemológico, es novedosa y pionera al contribuir con otra visión, que estudia, analiza y propone la entrevista como método del periodismo, al mostrar algunos hallazgos y abrir nuevas perspectivas sobre las teorías del periodismo.

Palabras clave: Periodismo. Reportaje. Metodología. Entrevista. Método. 


\begin{abstract}
Here the methods of reporting of journalists are described and analyzed, especially the processes of the reporter as mediator-narrator. The interview-encounterimplies a method that goes to the discovery of everyday experiences, and welcomes them with the affections and sympathies of understanding. In a dialogic approach, the narrative weaves the considerations and information that universalize the situation of everyday life. With this method the relations between conversation, observation and experienceexperience are established. A reflection is made on the interview encounter as a crosssectional method of journalism, research, testimonies, life stories and human narratives. In my book The report as a methodology of journalism. A polyphony of knowledge (2017) I argue that journalism shows and illuminates paths (methods) through reporting, which throughout the world has been widely studied as a journalistic genre, but not under the dimension of the methodology of journalism, which has been important to the eyes of scholars, theorists and academics. Considering the facts, my proposal constitutes an epistemological turn, it is inovative and pioneer in contributing with another vision, which studies, analyzes and proposes the interview as a method of journalism, by showing some findings and opening new perspectives on the theories of journalism.
\end{abstract}

Keywords: Journalism. Report. Methodology. Interview. Method.

Resumo: Aqui, os métodos de reportagem de jornalistas são descritos e analisados, especialmente os processos do repórter como mediador-narrador. A entrevista-encontroimplica um método que vai para a descoberta de experiências cotidianas e as acolhe com os afetos e simpatias da compreensão. Numa abordagem dialógica, a narrativa tece as considerações e informações que universalizam a situação da vida cotidiana. Dessa maneira (método) são estabelecidas as relações entre conversa, observação e experiência-experiência. É feita uma reflexão sobre o encontro da entrevista como um método transversal de jornalismo, pesquisa, testemunhos, histórias de vida e narrativas humanas. No meu livro O relatório como uma metodologia do jornalismo. Uma polifonia do conhecimento (2017) defendo que o jornalismo mostra e ilumina caminhos (métodos) através da reportagem, que em todo o mundo tem sido amplamente estudada como um gênero jornalístico, mas não sob a dimensão da metodologia do jornalismo, que tem sido escondida aos olhos de estudiosos, teóricos e acadêmicos. Nesse sentido, minha proposta constitui uma virada epistemológica, é inovadora e pioneira em contribuir com outra visão, que estuda, analisa e propõe a entrevista como método de jornalismo, mostrando algumas descobertas e abrindo novas perspectivas sobre as teorias do jornalismo.

Palabras clave: Jornalismo. Reportagem. Metodologia. Entrevista. Método. 


\section{Introducción}

El periodismo es libertad de pensamiento, de expresión y de diálogo social o conversación para poner en común y fortalecer el consenso y la participación democrática. En ese proceso, el periodismo muestra e ilumina caminos (métodos) a través del reportaje, que en todo el mundo ha sido muy estudiado como género periodístico; en torno a él se han publicado numerosos libros y artículos, y en diversas universidades se han otorgado títulos de doctorado por tesis realizadas sobre el tema. La bibliografía europea y estadounidense al respecto, que es abundante $-\mathrm{y}$ que he tenido en cuenta para esta investigación-, es de conocimiento general; pero se desconoce lo producido en nuestro propio continente. Por eso, en dicho libro me centré en dos ejemplos importantes: lo hecho en Brasil y en Colombia. Sin embargo, debo reiterar que cuando se aborda el tema propuesto se hace desde la óptica de los géneros periodísticos ${ }^{2}$, pero no bajo la dimensión de la "metodología del periodismo", que ha estado oculta a las miradas de estudiosos, teóricos y académicos. En este sentido, mi libro constituye un giro epistemológico, pues es novedoso y pionero al contribuir con otra visión, que estudia, analiza y propone el "reportaje como metodología del periodismo", al mostrar algunos hallazgos y al abrir nuevas perspectivas sobre las teorías del periodismo.

Como es de conocimiento general, la metodología es la ciencia de los métodos, además del conjunto de aquellos utilizados en una investigación, y está compuesta por dos grandes partes: la cuantitativa y la cualitativa, que a su vez comportan conjuntos de métodos. En la tradición, desde la perspectiva temporal, hay tres grandes grupos: el histórico, el descriptivo e interpretativo, y el experimental. Por otra parte, están los grupos de metodologías: en ciencias humanas y sociales, y en las artes.

La metodología del periodismo (el reportaje) ha contribuido históricamente, a través de la "reportería", al desarrollo de la investigación, con semejanzas y diferencias, apropiaciones y contribuciones a las demás formas de investigar de las ciencias sociales y humanas, en un proceso de diálogo, interdisciplinariedad y transdisciplinariedad. Pero, para llegar a ese punto, debemos recordar su origen y actividad central en el hacer del periodista.

El verbo latino reportare significa transmitir, descubrir, anunciar, traer nuevas. Re se antepone a los verbos y designa movimiento para atrás, ahí está el pasado. Portar es cargar consigo. Aquí tenemos el presente caminando hacia el futuro. Repor es recolocar, 
reconstituir. Así, reportar es (re)volver sobre sí. El periodista porte la parole (toma la palabra) para llevarnos de vuelta.

À portée de la voix (al alcance de la voz); una palabra antigua, reportare, se torna una expresión nueva, news report en inglés, reportage en italiano y francés, reportaje en español, reportagem en portugués. Portaletras, portavoz, o aun portavida, el neologismo implica una hermenéutica, porque es un arte de la interpretación y la comprensión; ya no de los textos sagrados sino de la vida misma. Para interpretar primero tenemos que comprender, y para eso necesitamos sumergirnos en el "humano ser". El reportar encierra en sí una pasión: el desafío de conocer, descubrir y relatar, no solo con el cerebro, sino también con el corazón, con todos los sentidos, y en los múltiples tiempos y espacios. Aquí está otra metodología de revivir lo acontecido.

El relato (narración y descripción) nació con el ser humano... sagas, leyendas, tradiciones, historias, cuentos, son la quintaesencia de los pueblos y componen la historia del mundo y los saberes variados. Las palabras están con nosotros desde siempre: como gemido, grito, sonoridad y voz. Ellas, primero orales y después escritas, cuentan la saga del viaje, quedan y construyen la memoria de mujeres y hombres que no se conforman con perder la vida intentando convertir lo temporal en eterno.

Sin embargo, los términos periodísticos modernos de "reportero" y "gacetillero" tienen sus orígenes en los rapportisti y los gazttani de Venecia. Gazzeta era una pequeña moneda veneciana con la que se pagaba la hoja suelta de noticias manuscritas que se vendía en establecimientos de la república mercantil. Los menanti: también conocidos como novellanti, rapportisti o gazzetanti, eran profesionales de la Italia del Renacimiento temprano, que ofrecían servicios de correspondencia de noticias para nobles y comerciantes. En Francia, los que hacían esas hojas, eran llamados nouvellistes o gazettiers (BALLE, 1991, p. 74).

El año 1440 marca el inicio de lo que Marshall McLuhan llama la "Galaxia gutenbergiana”. Gracias a este invento, las hojas manuscritas por los rapportisti ampliaron su esfera de circulación y de influencia. Las primeras hojas impresas tuvieron funciones diversas; algunas se limitaron a proporcionar noticias para enriquecer a sus impresores, mientras que otras buscaron difundir las nuevas ideas y proponer al público temas de reflexión sobre la realidad sociopolítica (GUTIÉRREZ, 2014, p.1).

Así, debemos profundizar en las raíces del reportaje para demostrar de qué está compuesta esa "metodología del periodismo", y la primera aproximación tiene que ver con su etimología: 


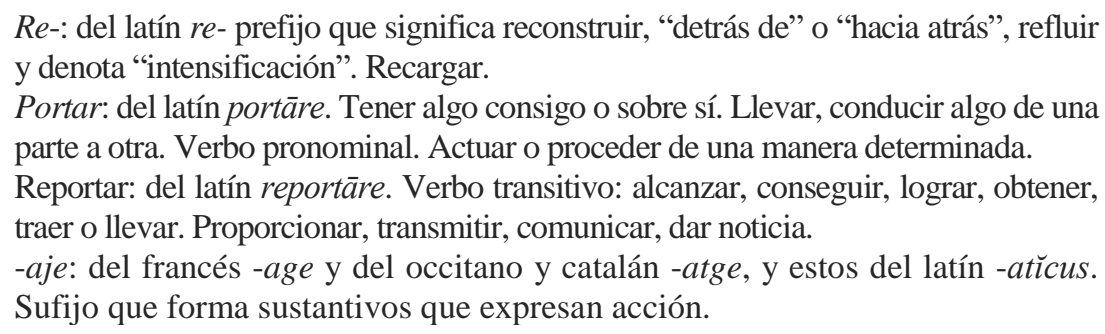

Es decir, el reportaje es la acción o sucesión de acontecimientos y hechos que constituyen su argumento, su argumentación. Del sufijo anticuado -adgo, y del sufijo latino aťcus que quiere decir condición o estado. Reportaticus o reportadgo, en fin reportaje... no solo un género periodístico, sino la "metodología del periodismo". El trabajo periodístico es un actuar y un proceder. Es el hacer del reportero para desarrollar el proceso de ejercicio de un reporte (noticia, informe, narrativa); es decir, reportear: la periodista que entrevista ${ }^{4}$ a alguien, el periodista que busca noticias y las difunde a través de diversos medios de comunicación. El "reportaje es una metodología" compuesta por diversos métodos y técnicas, las más utilizadas son: la observación, la observación participante y la entrevista en el proceso de la experienciavivencia. La reportería tiene como eje fundamental la primera, pues es el medio por excelencia para aprehender lo social que se manifiesta en la experiencia y señala los procedimientos para recoger los registros y situaciones que se viven en los contextos estudiados. A través de su experiencia-vivencia el reportero observa para participar y participa para observar.

El paradigma racionalista relegó la observación al nivel de lo precientífico; grosero error, porque este es un proceso de diversas modalidades, actitudes y grados de profundidad en el conocimiento humano. Las observaciones nos permiten a los periodistas estudiar las comunidades desde adentro, y este primer contacto proporciona una primera aproximación a la realidad, al tratar de llegar a una comprensión de lo que sucede y procurar conocer el punto de vista de la propia gente; es decir, conocer la lectura que estas personas hacen de la realidad. Por supuesto, hay muchas maneras de observar, pero la que históricamente ha usado el periodismo tiene que ver con la mirada flexible y abierta. La mirada del llamado mirón o flaneur, como lo llamaron los franceses.

\section{La búsqueda infinita...}

La espiral de visiones, que nos da el viaje por las ciudades, es fundamental para conocer el pasado e ingresar en la comprensión profunda, con imágenes más complejas DOI: http://dx.doi.org/ 10.14393/par-v4n2-2019-52192 Paradoxos, Uberlândia, v. 4, n. 2, p. 101-115, jul./dez. 2019 | 105 
de las urbes — escenas para zambullirse en las condiciones humanas y del paisaje- ; escuela de periodistas que buscan los rastros de lo antiguo y los caminos del presente, métodos que fluyen bajo el ritual de la expectativa del tiempo que vendrá generando la memoria rescatada, escenas que vienen de la calle, de los sentidos ${ }^{5}$ agudos del "humano ser". De la turbulenta realidad que se vuelve otra, así los reporteros construyen su expresividad, sus complejas manifestaciones asumen la heterogeneidad sin renunciar a lo universal, que siempre ha estado presente en su forma de ser, marcando su cultura en incontables variaciones para volverse un vehículo privilegiado de comunicación y expresión de sentimientos.

Los cronistas-reporteros de ciudad construyeron su metodología en la caminada. Una acertada definición de método es camino, "caminante no hay camino, se hace camino al andar", eso han hecho los periodistas con su inventiva. Es ir al encuentro de las travesías de los latinoamericanos; de campesinos que se mudaron para las ciudades.

En mi libro se encuentra una lectura que no es completa ni exhaustiva de los reportajes citadinos. Allí se buscó una filosofía del periodismo y una teoría del reportaje como metodología. En las metáforas, en los rasgos de estas narrativas, encontramos los modos de mirar el mundo del "Humano Ser". Ahí está la cosmovisión, el panorama variado de la multiplicidad de expresiones, las diversas hablas de profundas raíces populares. Medio de expresión del sentir urbano que no esquiva la realidad social, cultural y política. Aquí las voces son el producto y la expresión de la ciudad, cuyos temas y motivos van desde el amor hasta las situaciones de injusticia social. El bagaje cultural adquirido en las esquinas de las calles nos muestra a los sobrevivientes rurales en el espacio de la urbe, donde comienza la gestión de la polifonía de las voces que, aunque distintas y diversas, suenan juntas para hacer de las observaciones, de las apreciaciones, importantes detalles que se agregan a los grandes temas determinantes de las luces y de las sombras de nuestra cosmovisión en este siglo XXI. La cultura estimula nuevos estudios, nuevas lecturas, nuevas propuestas.

Los valores transmitidos por el reportaje de ciudad son la reivindicación de la cultura generada por los habitantes en su amalgama múltiple. Las palabras nos señalan el horizonte: pobres, de escasos recursos, indios, urbanos, sencillos; horizonte pleno de lógica metafórica, imagen, amor, sentimiento comunitario, diálogo posible y expresivo.

El reportaje esconde siempre algo de desconocido en espera de descubrimiento, en la búsqueda milenaria colecciona los tiempos humanos que continúan vivos en 
nuestras memorias, como culturas en diálogo, hostigadas por la necesidad de contar la trayectoria para saber (saborear) las leyes silenciosas que nos mueven y sentir los hilos de las épocas. Ahí encontramos la lucha por la vida, la lucha de los citadinos olvidados buscando su sentido universal en la aldea. El pasado está en todo. Raíces consagradas en lo cotidiano, en la búsqueda de modos, estilos en los secretos de la luz de la memoria. Poética y precisión al construir espacios, y detalles que iluminan los lugares, con la intención de comprender el espacio donde se vive. El ser humano dentro de su geografía, como la definió Milton Santos, la geografía es la historia del espacio y la historia la geografía del tiempo.

Al explorar lo que la persona sabe, ya que todo el mundo tiene un cofre, a pesar de que existan diversos y complejos tipos de memoria, se obtiene la diversidad de las voces y ese tono de algo sagrado. Así, ese signo heterogéneo es invertido, revertido, para alcanzar nuestra antropofagia; es eternamente reportaje. El mito del eterno retorno, la narrativa que siempre retorna para surcar por los caminos de la convivencia entre nosotros y el mundo, acompañando las diferentes etapas de la evolución humana, para que un nuevo grupo de narradores surja con toda la fuerza, reinterpretando y comprendiendo, cada uno a su manera, el viaje de la esperanza del "Humano Ser".

El reportaje es un ser en comunicación. La conversación se llama reportaje de las palabras, de los gestos, de las imágenes y de los diversos modos de comunicarse. Cada uno con su forma, a su modo, nutre nuestros diálogos humanos. Y a través de la narrativa encontramos la imagen de aquellos que son necesitados, en una ciudad afligida por el desempleo y la violencia, pero también en una ciudad con sus espacios de riqueza, desarrollo y bienestar. Y allí está el periodista para ponerse a dialogar con la ciudad como un todo humano, con sus diversos prismas, con sus múltiples hablas.

Al describir lugares y escenas en el tiempo, el reportaje-metodología se caracteriza como una especie de realismo mágico. La realidad es mágica por sí sola. No hay novedad en decir eso, pues los novelistas latinoamericanos han demostrado ese prisma de vida humana con una amplia marca de verdad y reconstitución histórica y, al mismo tiempo, han partido de una fina mirada lúcida para documentar y contextualizar la obra del mediador. Los héroes son verdaderos personajes de carne y hueso, seres de vida profunda con una cosmovisión del mundo. Son páginas abiertas a la voz de las personas que no tuvieron voz, los protagonistas de hechos sociales. El tema de los reportajes citadinos tiene libertad para la angulación, la entrevista, la captación. El habla es la 
sintonía para que el periodista recree desde su punto de vista y es su sensibilidad la que da el ritmo y el tono. Es como una danza en la era del tiempo.

Los reportajes citadinos son un espacio abierto a cada persona que contiene un universo lleno de sensibilidad, en el cual se establece un diálogo real para que no nos perdamos en la selva de la información globalizada, donde el "Humano Ser" termina siendo un número, un tornillo, una tuerca (aunque la gran ciudad sea el lugar y el momento en los que los sujetos se confrontan con el mundo contemporáneo, donde la vida material, del intelecto y del espíritu presentan una diversidad de formas de mudanza y de resistencia). Ciudad, modos de vida de la cultura urbana, tiempo febril de multitud, soledad y crisis. Ciudad, lugar privilegiado para la observación participante, que es un método de conocimiento de un mundo diferente nacido con la sociología en los últimos años del siglo XIX y primeros del siglo XX, y que navega con empatía y asombro por el modo de vida urbano y los enredos de la sociedad actual, en la que el perfil psicológico de los sujetos sugiere el tema del día, lugar de encuentro de las memorias diversas y oralidades de la metrópoli. El reportaje llega a otra sensibilidad, porque la ciudad es la gente... (OSORIO, 2017, p. 94-97).

[...] en una metodología para no solo reflexionar sobre cómo se hace el acto de reportar, sino también para entrar en la práctica del hacer. Ya que la "vida es la historia de un inconsciente que se realizó. Todo lo que en él reposa aspira a volverse acontecimiento"(JUNG, 1986, p. 13).

El viaje del héroe... en nuestro caso, de los antihéroes de ciudad, y en el cual también están presentes el diálogo escritura-oralidad. Porque como dice Cremilda Medina (1995, p.8), "más que el talento de algunos, poder narrar es una necesidad vital". Aunque en el principio fue el silencio. Luego vino la familia compuesta por millares de seres humanos. Cierto grupo de familias formaron una asociación, que la lengua griega llamó una fratría ${ }^{6}$ y la lengua latina una curia $^{7}$. Era una pequeña sociedad modelada exactamente sobre la familia. La asociación siguió aumentando y varias curias o fratrías se agruparon y formaron las tribus. Y corrieron los tiempos hasta que las tribus vieron la necesidad de asociarse. El día en que se celebró esa alianza nació la ciudad antigua, que era una confederación. Urbe y ciudad no eran la misma cosa. La ciudad era la asociación de las familias y de las tribus. La urbe era el lugar de reunión, el domicilio, y, sobre todo, el santuario de esta asociación. Hoy son sinónimos con un nuevo orden humano. El reportero camina para conocer la construcción de ese tejido polifónico, desplazándose y mezclándose en las esferas citadinas. "Vivir es crear esferas" nos ha dicho Sloterdijk ${ }^{8}$. Ciudades fronterizas, gigantescas cajas de resonancias situadas en el límite de lo colonial, lo moderno y 
lo posmoderno, y escenarios de hibridaciones en donde dejamos de ser habitantes para ser pasajeros de sus zonas de separación.

\begin{abstract}
La ciudad contemporánea y su infinidad de posibilidades, más allá de las calles, es un organismo vivo tejido de experiencias-vivencias compartidas. La ciudad es un vivificar las aventuras humanas, porque son las gentes quienes la viven y gracias a las seducciones de la conversación, de la entre-vista encuentro, del entre-ver más allá de los tiempos, se pueden conocer y narrar. Es decir, es posible conocer la ciudad en sus realidades complejas, contradictorias, intermedias y de tránsitos... ríos humanos, muchedumbres, laboratorios y espacios privilegiados de "comprensión humana", donde el reportero, mirador nómada, vive y construye el conocimiento del periodismo transeúnte, habitante formador de libertad y de opinión; en otras palabras, formador de ciudadanos, ya que las dinámicas urbanas prefiguran la asunción de otras formas de ser y de estar en el mundo (OSORIO, 2017, p. 98-99).
\end{abstract}

\title{
La entre-vista-encuentro
}

La conversación o entre-vista encuentro es un método fundamental de la “metodología del reportaje" ya que nos permite entre-ver más allá de las superficies y comprender en profundidad para narrar. ¿Entrevistar para qué? Entre-vista, mirada, escuchada y sentida como diálogo, encuentro, conversación profunda de comunión, método del reportaje que produce conocimiento. Diálogo polifónico que transforma una entrevista de campo en un experimento en igualdad.

Aquí está la entrevista: el camino del encuentro con el otro. En el trabajo del reportero la entrevista es la vía para procurar las expresiones humanas que permanecen en el umbral de la parte más íntima de la cultura. Sabemos que tanto el reportaje escrito como el transmedia se encuentran precedidos por el habla, y el arte de narrar es parte de la vida misma, integrada a las manifestaciones sociales. La entrevista que sale de lo cotidiano, del "humano ser", teje las historias que son parte del acontecimiento en la comunidad. Para revivir el pasado y fijar el presente tenemos que ir a través de nuestra oralidad, y debemos reinstaurar la vieja práctica del diálogo entre los humanos, donde las diversas partes salen enriquecidas.

La metodología del reportaje depende de entrevistas con personas, sujetos de investigación o narradores, que son nuestros colaboradores y compañeros en el proyecto. Pero lo que emerge de esos testimonios es la versión de los hechos, por eso las entrevistas siempre estuvieron en el orden del día, en la forma o manera de captación de las 
experiencias de vida. El escuchar con oídos refinados es el camino de mayor reflexión y tiempo, un dominio del arte de escuchar al otro y vivir en sintonía con él. Las conversaciones de los reporteros con sus entrevistados muestran los caminos de comunicación, es decir comunión. Por esos caminos el reportero desarrolla la entrevista más allá de la técnica, en sus virtudes dialógicas. La investigadora brasileña, Cremilda Medina (1995, p.7) propone:

En el cotidiano del hombre contemporáneo hay espacio para el diálogo posible. Ahí están experiencias o excepciones de la regla que promueven el grado de concretización de la entrevista en la comunicación colectiva. Su mayor o menor comunicación está directamente relacionada con la humanización del contacto interactivo: cuando, en uno de esos momentos raros, ambos — entrevistado y entrevistador - salen "alterados" del encuentro, la técnica fue ultrapasada por la "intimidad" entre el yo y el Tú.

En esta visión, la entrevista es la esencia del periodismo de calidad y el método del reportaje. Así mismo, en las ciencias humanas la entrevista evoca, y aún evocará un gigantesco trabajo crítico y metodológico. La entrevista, evidentemente, se funde en la más dudosa y rica de las fuentes, la palabra. Ella corre el riesgo permanente de la disimulación o de la fabulación. La pregunta abierta y la respuesta espontánea permiten (y, sobre todo, para el análisis profundo) a la vez la fabulación, la sensibilidad verídica y una riqueza de significados: pero, esta vez, el riesgo máximo de error se sitúa del lado del entrevistador, de su capacidad para descifrar el mensaje del entrevistado. El entrevistador debe poseer un grado raro de dotes de objetivación y de participación subjetiva. Lo que significa que el reportero deberá estar a la altura de un papel de confesor laico de la vida moderna.

Aquí está el porqué de la entrevista que proviene de la palabra francesa entrevoir, que significa "verse recíprocamente", o mejor mezclarse, como ha sucedido durante siglos en Nuestra América Mestiza. Proceso de transculturación. Esta noción de entrevista como método, camino al encuentro, va de la mano de la experiencia-acción; pero acción más allá de las presencias físicas, abarcando la acción-sobre-la-experiencia propia o de los otros. Experiencia como conocimiento en movimiento, vivencia con participación del sujeto, es decir, la experiencia de lo vivido, métodos del reportaje y campo de las ciencias humanas: antropología, filosofía, historia, psicología, semiótica, sociología, todas preocupadas en desvendar la comunicación con el otro, o sea, la comunión en proceso. Por tanto, la comunicación se convierte solo en un "espacio", una encrucijada donde las diversas áreas de las ciencias sociales y humanas se encuentran y se funden. Ahí 
encontramos la emergencia del sujeto humano en la experiencia-acción hablada, un fenómeno muy poderoso en América Latina, donde las mayorías viven en la cultura oral: expresión de su visión de mundo, del sentir, del pensar, del amar.

La entrevista no es solo un instrumento o una herramienta y sí un método, dentro de un proceso que aborda la esencia de nuestra experiencia subjetiva, para llegar a las versiones de la vida y no a una verdad de los hechos del mundo. Entrevista, efervescencia sagrada de comunión. Pero, ¿qué es la entrevista vista desde adentro? Un ritual complejo no solo en el exterior, sino también en el interior del encuentro sujeto-sujeto, en la confesión de seres humanos que viven tiempos extraordinarios de turbulencias y de urgencias afectivas, buscando su camino entre lo sagrado y lo profano, donde el modo complejo de caminar-pensar:

[...] se impone de entrada como imposibilidad de simplificar; ella surge allí donde la unidad compleja produce sus emergencias, allí donde se pierden las distinciones y claridades en las identidades y causalidades, allí donde los desórdenes y las incertidumbres pertuban los fenómenos, allí donde el sujeto-observador sorprende su propio rostro en el objeto de su observación (MORIN, 1977, p. 377-378).

Entrevista, inteligencia en acción que transforma el subsuelo de los seres vividos, llenos de experiencia, que abren sus corazones y cuentan sus complejidades, porque la historia está dentro de nosotros, esa cosa natural que la gente lleva consigo, en el yo principio de la unidad, el yo incluido en el otro yo. Encuentro como método de conocimiento y red de conexiones entre las personas, los hechos y el mundo. La experiencia vivida guía la entrevista en el diálogo, en la conversación, en el encuentro rumbo a la alteridad, esa comunión de intimidad en la conciencia de cada uno. La vivencia como experiencia de vida es el momento en que se puede producir la revelación del otro en profundidad. En el método de la entrevista, el observador participante entra en la realidad de su sujeto de investigación a través de la empatía. Ya que podemos tener la libertad de ver al otro como se vive el arte:

Una novela, un poema, un cuadro, una pieza musical son individuos, eso es, seres en los que puede distinguirse la expresión de lo expresado, cuyo sentido solo es accesible por un contacto directo y que irradian su significación sin abandonar su lugar temporal y espacial. Es en este sentido que nuestro cuerpo es comparable a la obra de arte (MERLEAU-PONTY, 1971, p. 162).

Pero nuestra existencia debe ser contextualizada. Contextos que son encuentro de temporalidades concretas y que se constituyen en redes de diálogos. Es que somos sujetos que vivimos en diferentes comunidades con especialidades y temporalidades propias y 
porosas, que componen la dimensión del pluralismo humano. En estas redes de transculturación ${ }^{9}$ vivimos la experiencia de observadores; pero más allá del observador participante proponemos el observador de la experiencia transcultural, a partir de dentro de sí y del otro. En otras palabras, un sabor-saber del acto de la entrevista en el reportaje como metodología del periodismo. Entrevista, espacio sagrado en un momento ritual, donde los sujetos participantes se relacionan (entre sî) dentro del territorio de la comunión. Aquí no hay espectadores, solo actores participantes que por medio de su diálogo convierten su encuentro cada vez más intenso y envolvente, procurando una fusión en las relaciones que sucesivamente cada uno vive, para experimentar el clima "encontrado" en las mutaciones de la historia oral de vida, donde se produce un grado "escrito" de lo hablado y un "hablado" de lo escrito: vía metafórica de la entonación afectiva compleja.

\section{Reportar lo entre-visto}

En esta propuesta del reportaje como metodología del periodismo la entre-vistaencuentro, el intercambio humano, el diálogo posible, es un movimiento y un acto que puede tornarse un "sacramento"; es decir, una comunión con el otro. Es la historia de los seres humanos que viven en la oralidad y expresan para el otro las necesidades propias de las experiencias vividas. Es el taller metodológico de la narrativa contemporánea, caminos de los sabios anónimos, experimentadores de la ensayística comunicativa llamada periodismo.

Los participantes de esta comunión afectiva, conscientes de los deberes que asumen, rompen el tecnicismo para generar una narrativa del sujeto presente en el mundo, integrado a su vivencia-acción, formada en la intimidad de la conciencia, de cada uno de los asociados al encuentro, donde las existencias son como las páginas en el libro del tiempo. Mediaciones que viven en los individuos y en las relaciones sociales y culturales, donde nace y crece el reportaje experiencial como modulación de las oralidades participativas y laboratorio de la identidad cultural de la vida cotidiana. El reportero de las realidades, como ser integrante de la sociedad, se funde con su sujeto-objeto de estudio. Rumbo que nos adentra por los "laberintos" de las transculturaciones, donde la intuición es otro de los métodos del conocimiento en la metodología del reportaje. Así, los reporteros vamos aglutinando métodos, caminos, para viajar en el proceso del conocimiento de vida de los otros. Transmétodos para llegar a nuestro destino, donde cada acto social tiene un sentido especial que 
solo cobra significado en los valores compartidos por los individuos de la sociedad. En esos múltiples caminos, el reportero investigador va a captar los hechos que le permitan encontrar los motivos subjetivos que impulsan el comportamiento del "humano ser". En la vía de la comprensión, que implica la inmersión en las vivencias íntimas, se reviven, en la mente del reportero, los elementos de las situaciones en contextos. Por esos métodos el reportaje es una metodología social que se apoya en la interiorización cada vez mayor, en la ley escrita en el corazón: sabemos lo que está afuera por lo que está adentro, pero lo que está adentro es, también, la aprehensión de lo que está afuera, dependiendo de los grados y niveles de refinamiento alcanzados.

Para llegar a la esencia de los acontecimientos tenemos que despertar aquellas facultades congénitas que permiten ver más allá de la apariencia de los fenómenos. En ese proceso profundo, lo que el reportaje expresa y comprende es el cotidiano de la vida. ¿Pero dónde comienza dicho camino? Por el núcleo, el lugar escondido y secreto de la consciencia, ese órgano central, bien visible y relativamente grande del individuo: el corazón. Es él quien reproduce, por un complejo proceso, la memoria. Para los uitotos (Amazonía de Colombia y Perú) corazón, pecho, memoria y pensamiento son la misma cosa. Si Occidente hizo del corazón la sede de los sentimientos todas las civilizaciones tradicionales, por el contrario, localizan en él la inteligencia y la intuición: tal vez el centro de la personalidad se haya dislocado de la intelectualidad hacia la afectividad. Pero, ¿Pascal no dijo que los grandes pensamientos vienen del corazón? Se puede agregar que, en las culturas tradicionales, conocimiento tiene sentido muy amplio, que no excluye los valores afectivos. Pascal vio el universo como una esfera infinita, cuyo centro está en toda parte, y el centro de nosotros es el corazón, que junto con los sentidos teje el ritmo de la existencia. Reconocer sus poderes es recrear la realidad, que siempre está presente, es fundar la afectividad que es muy deseada por la curiosidad de ver, saber, desvendar, aprender, conocer, despertar, descubrir, identificar; pero, especialmente, observar, lo que es contemplación (theoria) y participación de todos nuestros sentidos para la comprensión del "humano ser".

\section{Referencias}

Ackerman, D. Una historia natural de los sentidos. Barcelona: Anagrama, 1993.

Aguilera, O. La literatura en el periodismo y otros estudios en torno a la libertad y el mensaje informativo. Madrid: Paraninfo, 1992. 
Balle, F. Comunicación y Sociedad: Evolución y análisis comparativo de los medios. Bogotá: Tercer Mundo Editores, 1991.

Borrat, H. El periódico, actor político. Barcelona: Gustavo Gili, 1989.

Chillón, A. Literatura y periodismo. Una tradición de relaciones promiscuas. Barcelona: Universidad Autónoma de Barcelona, 1999. https://doi.org/10.7203/puv-alg28-9460-1

Chillón, A. La palabra facticia. Literatura, periodismo y comunicación. Barcelona: Universidad Autónoma de Barcelona, 2014.

García, G. Sofismas de distracción, Sala de Prensa, 2001. Recuperado de http://www.saladeprensa.org/art201.htm

Gargurevich, J. Géneros periodísticos. Quito: Ciespal, 1982.

Grijelmo, Á. El estilo del periodista. Madrid: Santillana, 2001.

Gutiérrez, J. Periodismo de opinión. Madrid: Paraninfo, 1984.

Hernando, L. A. El discurso periodístico. Madrid: Verbum, 2000.

Jung, C. G. O pensamento vivo de Jung. São Paulo: Martin Claret, 1986.

Malinowski, B. Introducción. En F. Ortiz, Contrapunteo cubano del tabaco y el azúcar. Caracas: Biblioteca Ayacucho, 1978.

Martín, G. Géneros periodísticos. Madrid: Paraninfo, 1973.

Martínez, J. L. Curso general de redacción periodística. Barcelona: Mitre, 1983.

Martínez, F. Herramientas periodísticas. Salamanca: Librería Cervantes, 1996.

Matute, Á. Crónica: historia o literatura. Historia mexicana. México: Colegio de México, 1996.

Medina, C. Entrevista o diálogo possível. São Paulo: Ática, 1995.

Melo, J. Teoria do Jornalismo: Identidades Brasileiras. São Paulo: Paulos, 2006.

Merleau-Ponty, M. Fenomenologia da Percepção. Río de Janeiro: Freitas Bastos, 1971.

Mignolo, W. Cartas, crónicas y relaciones del descubrimiento y la conquista. En Historia de la literatura hispanoamericana. I. Época colonial. Madrid: Cátedra, 1982, p. 57-102.

Monsiváis, C. De la hora del ángelus a la del zapping. La crónica en América Latina. Letras Libres, 2005, p. 50-58.

Monsiváis, C. A ustedes les consta. Antología de la crónica en México. México: Ediciones Era, 2010. 
Morin, E. La Methode: Tomo 1. Paris: Les éditions du Seuil, 1977.

Osorio, R. El reportaje como metodología del periodismo. Una polifonía de saberes. Medellín: Editorial Universidad de Antioquia, 2017.

Rotker, S. Fundación de una escritura. Las crónicas de José Martí. La Habana: Casa de las Américas, 1992. https://doi.org/10.2307/4530783

Vilamor, J. R. Redacción periodística para la generación digital. Madrid: Universitas, 2000.

Yanes, R. La crónica, un género del periodismo literario equidistante entre la información y la interpretación. Espéculo. Revista de Estudios Literarios, 2006. Recuperado de https://pendientedemigracion.ucm.es/info/especulo/numero32/cronica.html. https://doi.org/10.12795/rihc.2018.i11.11

Data Recebimento: 09/2019

Data Aprovação: 11/2019

${ }^{1}$ Profesor Titular de la Universidad de Antioquia. Magíster (1999) y Doctor (2003) en Ciencias de la Comunicación, área de Concentración Epistemología del Periodismo por la Escuela de Comunicaciones y Artes de la Universidad de São Paulo. Con 38 años de experiencia profesional ha trabajado en diversos medios de comunicación como reportero, redactor, columnista, editor y director. Correo electrónico: osoriova@ gmail.com

2 Aguilera (1992), Borrat (1989), Chillón (1999), Grijelmo (2001), Gutiérrez (1984), Hernando (2000), Martín (1973), Martínez (1983), Martínez (1996), Matute (1996), Mignolo (1982), Monsiváis (2005), Rotker (1992), Vilamor (2000), White (1992) y Yanes (2006). Entre variados estudios que se han realizado en el mundo. La lista es extensa y amplia.

${ }^{3}$ Neologismo tradicionalmente aceptado para el trabajo de campo de los periodistas. Por los principios de "reportería" del periodismo sabemos que la búsqueda de la información comienza con la asignación periodística, que es el primer paso en la elaboración de un artículo noticioso, que se debe considerar simultáneamente como un proyecto de investigación y un problema que es necesario resolver.

${ }_{5}^{4}$ En el presente texto profundizo sobre la entrevista como método.

5 "El mundo es un manjar sabroso para los sentidos. [...] No hay modo de comprender el mundo sin detectarlo antes con el radar de los sentidos. [...] Nuestros sentidos definen las fronteras de la conciencia y, como somos exploradores e investigadores innatos de lo desconocido, pasamos una gran parte de nuestra vida recorriendo ese parámetro turbulento" (ACKERMAN, 1993, p. 13).

${ }^{6}$ Entre los antiguos griegos, subdivisión de una tribu que tenía sacrificios y ritos propios.

${ }^{7}$ Una de las divisiones del antiguo pueblo romano. La constituía la corte, la familia y la comitiva del rey.

${ }^{8}$ Peter Sloterdijk es un filósofo y catedrático alemán de la Escuela de Arte y Diseño de Karlsruhe, Alemania. Su trilogía Esferas reflexiona sobre la comprensión de lo cercano, los sentidos y las sensaciones.

9 "Todo cambio de cultura, o como diremos desde ahora, toda transculturación, es un proceso en el cual siempre se da algo a cambio de lo que se recibe; es un 'toma y daca', como dicen los castellanos. Es un proceso en el cual ambas partes de la ecuación resultan modificadas. Un proceso en el cual emerge una nueva realidad, compuesta y compleja; una realidad que no es una aglomeración mecánica de caracteres, ni siquiera un mosaico, sino un fenómeno nuevo, original e independiente. Para describir tal proceso el vocablo de latinas raíces trans-culturación proporciona un término que no contiene la implicación de una cierta cultura hacia la cual tiene que tender la otra, sino una transición entre dos culturas, ambas activas, ambas contribuyentes con sendos aportes, y ambas cooperantes al advenimiento de una nueva realidad de civilización” (MALINOWSKI, 1978, pp. 4-5). 